\title{
Persistence of experimental Rocio virus infection in the golden hamster (Mesocricetus auratus)
}

\author{
Daniele Freitas Henriques ${ }^{1}$, Juarez Antonio Simões Quaresma ${ }^{2,3}$, \\ Helen Thais Fuziii ${ }^{2}$, Márcio Roberto Teixeira Nunes ${ }^{1}$, Eliana Vieira Pinto da Silva ${ }^{1}$, \\ Valéria Lima Carvalho', Lívia Carício Martins ${ }^{1}$, Samir Mansour Moraes Cassebb \\ Jannifer Oliveira Chiang1, Pedro Fernando da Costa Vasconcelos ${ }^{1,3} /+$
}

'Departamento de Arbovirologia e Febres Hemorrágicas, Instituto Evandro Chagas, Ananindeua, PA, Brasil ${ }^{2}$ Núcleo de Medicina Tropical, Universidade Federal do Pará, Belém, PA, Brasil ${ }^{3}$ Departamento de Patologia, Universidade do Estado do Pará, Belém, PA, Brasil

Rocio virus (ROCV) is an encephalitic flavivirus endemic to Brazil. Experimental flavivirus infections have previously demonstrated a persistent infection and, in this study, we investigated the persistence of ROCV infection in golden hamsters (Mesocricetus auratus). The hamsters were infected intraperitoneally with $9.8 \mathrm{LD} \mathrm{D}_{50} / 0.02 \mathrm{~mL}$ of ROCV and later anaesthetised and sacrificed at various time points over a 120-day period to collect of blood, urine and organ samples. The viral titres were quantified by real-time-polymerase chain reaction (qRT-PCR). The specimens were used to infect Vero cells and ROCV antigens in the cells were detected by immunefluorescence assay. The levels of antibodies were determined by the haemagglutination inhibition technique. A histopathological examination was performed on the tissues by staining with haematoxylin-eosin and detecting viral antigens by immunohistochemistry (IHC). ROCV induced a strong immune response and was pathogenic in hamsters through neuroinvasion. ROCV was recovered from Vero cells exposed to samples from the viscera, brain, blood, serum and urine and was detected by $\mathrm{q} R T-P C R$ in the brain, liver and blood for three months after infection. ROCV induced histopathological changes and the expression of viral antigens, which were detected by IHC in the liver, kidney, lung and brain up to four months after infection. These findings show that ROCV is pathogenic to golden hamsters and has the capacity to cause persistent infection in animals after intraperitoneal infection.

Key words: Rocio virus - flavivirus - persistent infection - golden hamsters - pathogenesis of experimental infection

Rocio virus (ROCV) was first described in 1975 as the causative agent of an encephalitis epidemic in humans that occurred in the Ribeira Valley area of the southern coast of the state of São Paulo (SP), Brazil (Tiriba 1975, Tiriba et al. 1976, Lopes et al. 1978, Pinheiro et al. 1997). The prototypical viral strain was isolated in that same year from the cerebellum and spinal cord of a fatal human case of encephalitis (Karabatsos 1985). The epidemic lasted seven years and more than 1,000 cases of encephalitis were reported, including 100 deaths and more than 200 cases of severe central nervous system (CNS) sequelae (Iversson 1988, Iversson et al. 1992). During the same period, five cases of encephalitis were reported in the northeastern region of the state of Paraná in areas bordering the affected region of SP (Straatmann et al. 1997).

In May 1995, during a dengue virus type 2 epidemic in the city of Salvador, three patients who were initially suspected to be infected with dengue virus presented with IgM antibodies against ROCV. The presence of neutralising antibodies to ROCV was confirmed in two of these cases. These two patients had chronic head-

Financial support: CNPq (573739/2008-0, 301641/2010-2), CAPES, FAPESPA

+ Corresponding author: pedrovasconcelos@iec.pa.gov.br Received 27 October 2011

Accepted 2 February 2012 aches. The three patients reported no travel outside of the city of Salvador during the six months prior to infection (Straatmann et al. 1997).

The biological cycle of ROCV is not completely understood, but most likely involves an arthropod vector and susceptible vertebrate host, which would categorise the virus as an arbovirus in the genus Flavivirus, family Flaviviridae (Fauquet et al. 2005). There is strong evidence that the virus circulates among ornithophilic mosquitoes and wild birds (Mitchell et al. 1986).

Members of the genus Flavivirus have an important public health impact worldwide. More than $50 \%$ of the known flaviviruses have been associated with human diseases and can cause conditions ranging from haemorrhagic fever, in the case of yellow fever virus, and dengue virus, to encephalitis, in the case of Saint Louis encephalitis virus, Japanese encephalitis virus, West Nile virus and ROCV, among others (Travassos da Rosa et al. 1997, Vasconcelos et al. 1998, Fauquet et al. 2005).

Advances in modern virology have revealed that persistent viral infections are common among flaviviruses. To cause a persistent infection, the virus must actively reduce the antiviral immune response of the host. Thus, as an important part of persistent viral replication, the virus disrupts the homeostasis of the host by causing disease without destroying the infected cell (Oldstone 2005). Persistent infection with other flaviviruses has been reported in in vitro and in vivo studies and in case reports. Indeed, in an experimental study, Siirin et al. (2007) demonstrated that adult hamsters infected with 
Saint Louis encephalitis virus continued to excrete the virus in urine for a prolonged period of time despite a robust immune response. These findings were similar to those reported for chronic infections with West Nile virus (Tesh et al. 2005, Tonry et al. 2005).

Therefore, the objective of the present study was to investigate the possible occurrence of persistent ROCV infections in vivo using young golden hamsters (Mesocricetus auratus) as the experimental model.

\section{MATERIALS AND METHODS}

Virus - ROCV strain SP H 34675 from the collection of the Section of Arbovirology and Hemorrhagic Fever, Evandro Chagas Institute (IEC), was selected for this study. This strain was obtained from the 10th passage of the virus in newborn Swiss albino mice and has an $\mathrm{LD}_{50}$ titre of 9.8/0.02 mL.

Animals-Forty-five two-three-week-old female golden hamsters ( $M$. auratus) were obtained from the animal care facility of IEC. The use of these animals was approved by the Ethical Committee on Animal Experimentation/IEC/ Secretary of Health Surveillance/Health Ministry.

Study design - The ROCV suspension inoculated into the hamsters was prepared from the brains of newborn Swiss albino mice infected with the viral strain. The brains were macerated in phosphate buffered saline (PBS), pH 7.4, containing 0.75\% bovine albumin fraction $\mathrm{V}$ and antibiotics. The suspension, which contained approximately $10^{3}$ plaque-forming units $(\mathrm{PFU}) / 0.1 \mathrm{~mL}$ based on a plaque assay in Vero cells, was inoculated intraperitoneally into 30 hamsters. Fifteen non-inoculated animals served as negative controls. Three hamsters (2 animals infected with the viral strain and 1 animal from the control group) were anaesthetised and sacrificed at intervals of $24 \mathrm{~h}$ for seven days and then at intervals of 15 days over a period of four months (120 days) postinfection (p.i.) for the collection of blood, urine, liver, spleen, kidneys, lungs, heart and brain samples. Aliquots of the blood, serum and urine were stored at $-70^{\circ} \mathrm{C}$ prior to analysis for viraemia and the detection of antigens and/or antibodies. The viscera and brain were divided into two parts. One part was stored at $-70^{\circ} \mathrm{C}$ and used for the detection of viral antigens by an indirect fluorescent assay (IFA) and virus titration by real-time-polymerase chain reaction (RT-PCR). The other part was fixed in $10 \%$ buffered formalin and used for histopathological analysis and immunohistochemistry.

Serological tests - Specific antibodies against ROCV were detected in the sera of hamsters collected during the experiment by the haemagglutination inhibition (HI) assay, as described by Clarke and Casals (1958) and adapted to microplates by Shope (1963). The antigen used was extracted from the brains of newborn Swiss albino mice infected with ROCV by the sucrose-acetone method (Beaty et al. 1989). The hamster sera were tested against four haemagglutination units of ROCV antigen in an $\mathrm{HI}$ assay using two-fold serial dilutions from 1:20-1:5,120.

Virus assay - For in vitro culture, organ fragments, blood, serum and urine were inoculated into Vero cells as described by Lennette (1995). The inocula were prepared from macerated organ fragments diluted 1:10 in PBS, $\mathrm{pH} 7.4$, containing $0.75 \%$ bovine albumin fraction $\mathrm{V}$ and antibiotics. The suspension was centrifuged at $8,000 \mathrm{rpm}$ for $10 \mathrm{~min}$ at $4^{\circ} \mathrm{C}$. The supernatant was then diluted 1:100 in maintenance medium for inoculation. The blood, serum and urine were directly diluted 1:50 in maintenance medium for inoculation. The inoculated specimens were examined daily under an inverted microscope (Olympus CK-2) to detect cytopathic effects (CPE). Infection with the virus was confirmed by IFA according to the method of Tesh (1979).

$R T-P C R$ - The virus was quantified in blood, brain fragments and liver collected during the experiment (3 months p.i. with ROCV) by reverse transcription followed by quantified RT-PCR ( $q$ RT-PCR) using the 7500 Real-Time PCR system (Applied Biosystems, USA). After extraction of viral RNA from the samples with Trizol LS (Invitrogen, USA), the reaction was performed with the SuperScript III Platinum SYBR Green One-Step $q$ RT-PCR kit (Invitrogen). The reaction mixture contained $0.5 \mu \mathrm{L}$ SuperScript III RT Platinum Taq Mix, 0.2 $\mu \mathrm{M}$ each of the ROCV-specific primers developed for this study [ROCV/NS5R (5'-GCT TCTGGAGTCCCT TTCCT-3') and ROCV/NS5F (5'-GGCAAGGTTTCT TGAGTTCG-3')], $12.5 \mu \mathrm{L} 2 \mathrm{x}$ YBR Green and $5 \mu \mathrm{L}$ extracted RNA in a final volume of $25 \mu \mathrm{L}$. The amplification conditions were as follows: (i) reverse transcription at $50^{\circ} \mathrm{C}$ for $3 \mathrm{~min}$, (ii) denaturation at $95^{\circ} \mathrm{C}$ for $5 \mathrm{~min}$ and (iii) PCR consisting of 40 cycles of denaturation at $95^{\circ} \mathrm{C}$ for $15 \mathrm{~s}$, annealing at $55^{\circ} \mathrm{C}$ for $1 \mathrm{~min}$ and extension at $72^{\circ} \mathrm{C}$ for $30 \mathrm{~s}$. The melting temperature $(\mathrm{Tm})$ of the specific amplicons ranged from $79.8-82^{\circ} \mathrm{C}$.

The results of the $q$ RT-PCR were analysed according to a standard curve, which was constructed by plating the positive ROCV control in Vero cells as described by Kuno (1998) and Nunes et al. (2011) to determine the virus titres, which were used as a reference for the dilution of viral RNA extracted from the control virus. Each dilution was submitted to $q$ RT-PCR to construct the standard curve and the virus titres were reported as PFU $/ \mathrm{mL}$.

Histopathological and immunohistochemical analyses - After fixation in formalin, the viscera (liver, spleen, kidneys, lungs, heart) and nerve tissue fragments were immersed in an increasing alcohol series $(70-100 \%$ ethanol), followed by two passages in xylene at room temperature and immersion in two paraffin baths at $60^{\circ} \mathrm{C}$. Finally, the specimens were embedded in paraffin blocks. After cooling, the blocks were cut with a rotary microtome (Jung Histocult 820, Leica) into 5- $\mu$ m-thick sections. The sections were stained with haematoxylineosin (Prophet et al. 1992) and submitted to immunohistochemical analysis with a peroxidase system according to the protocol of Carvalho et al. (2009).

\section{RESULTS}

Clinical findings - The 30 hamsters inoculated with the ROCV suspension and the 15 hamsters used as negative controls remained active and showed no signs of disease during the experiment. 
Detection of haemagglutination-inhibition antibodies - HI antibodies against ROCV were detected in the sera collected after day 5 p.i. (1:480) and increased until reaching a maximal titre $(1: 1280)$ on day 15 . Thereafter, the antibody titres declined until day 45 p.i. and remained almost unchanged until the end of the experiment (4 months p.i.). The HI antibody kinetics are shown in Fig. 1.

Virus isolation in Vero cells confirmed by indirect immunofluorescence assay - The analysis of biological samples from hamsters infected with ROCV collected on day 1 p.i. confirmed viral replication only in the blood. However, ROCV antigens were already detected on day 2 p.i. in the supernatants of cells inoculated with infected blood, serum, urine, liver, kidney, spleen, lung and brain samples. The supernatants of cells inoculated with tissues, blood and serum collected on day 3 p.i. tested positive when homologous serum (anti-ROCV) was used. After infection with ROCV, no viral antigens were detected in the supernatants of cells inoculated with serum and urine collected on day 4 p.i. or serum, blood, urine and liver collected on day 5 p.i. ROCV antigens were detected in the supernatants of cells inoculated with heart and brain samples collected on day 6 p.i. Biological materials collected between seven-120 days p.i. from ROCV-infected hamsters and inoculated into Vero cells were negative for ROCV antigens (Table). ROCV antigen-positive samples had CPE against Vero cells that were characterised by the destruction of the cell monolayer due to cell death.

Viraemia curve - $q$ RT-PCR was found to be highly sensitive and specific for ROCV. The analysis of the dissociation curve showed that the Tm of the specific amplicons ranged from $79.8-82^{\circ} \mathrm{C}$. The cycle threshold values of serial dilutions of ROCV ranged from 14.6525.23. Viral RNA was detected in the brain, liver and blood samples collected after day 1 p.i. The viral load increased until reaching a maximum titre on day 4 p.i. for liver samples and on day 5 for brain and blood samples, followed by a decline in the viral titre. The viral load then remained almost unchanged until the end of the experiment (3 months p.i.) (Fig. 2).
Characterisation of the immunohistopathological alterations observed in ROCV infection - The infection of the golden hamster with ROCV caused intense tissue damage (Fig. 3) in the liver, lung, kidney and brains, although small injuries were also observed in the heart and spleen. The latter were characterised by oedema accompanied by mononuclear infiltration of spaces among the myocardiocytes and spleen hyperplasia, which conferred a reactive appearance.

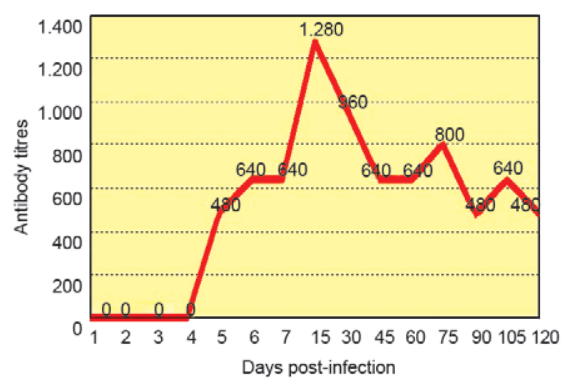

Fig. 1: titres of specific antibodies against Rocio virus in sera kinetic of infected hamsters.

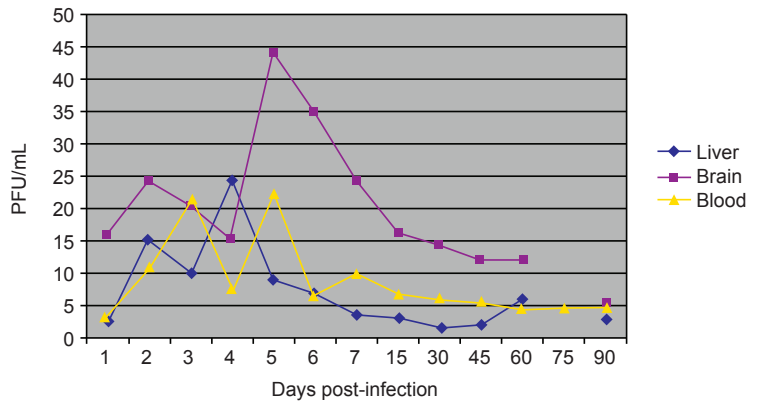

Fig. 2: Rocio virus load in the liver, brain and blood of infected hamsters reported as plaque-forming units $(\mathrm{PFU}) / \mathrm{mL}$ at different days post-infection.

TABLE

Rocio virus (ROCV) titres according to the percentage of viral antigens observed, by biological samples and days post-infection (p.i.)

\begin{tabular}{lccccccc}
\hline $\begin{array}{l}\text { ROCV-infected } \\
\text { sample }\end{array}$ & $\begin{array}{c}\text { Day } 1 \\
\text { p.i. }\end{array}$ & $\begin{array}{c}\text { Day } 2 \\
\text { p.i. }\end{array}$ & $\begin{array}{c}\text { Day } 3 \\
\text { p.i. }\end{array}$ & $\begin{array}{c}\text { Day } 4 \\
\text { p.i. }\end{array}$ & $\begin{array}{c}\text { Day } 5 \\
\text { p.i. }\end{array}$ & $\begin{array}{c}\text { Day 6 } \\
\text { p.i. }\end{array}$ & $\begin{array}{c}\text { Day 7-120 } \\
\text { p.i. }\end{array}$ \\
\hline Liver & - & ++ & +++ & +++ & - & - & - \\
Kidney & - & +++ & +++ & +++ & ++ & - & - \\
Spleen & - & ++ & +++ & +++ & +++ & - & - \\
Lung & - & ++ & +++ & +++ & +++ & - & - \\
Heart & - & - & ++ & +++ & +++ & + & - \\
Brain & - & + & ++ & +++ & +++ & - & - \\
Blood & ++ & +++ & +++ & ++ & - & - & - \\
Serum & - & ++ & ++ & - & - & - & - \\
Urine & n.i. & +++ & - & - & - & - & -
\end{tabular}

n.i.: not inoculated; -: negative; $+: 25 \%$ of the field; $++: 50 \%$ of the field; $+++: \geq 75 \%$ of the field. 
The histological analysis of the livers from hamsters infected with ROCV revealed hepatocyte ballooning and portal spaces filled with a mononuclear infiltrate. A discrete to moderate mononuclear infiltrate was observed and necrotising or apoptotic hepatocytes were frequent (Fig. 3B). There was no evidence of cholestasis or a preference for a specific Rappaport area. The portal spaces were swollen and filled with an infiltrate of lymphocytes and plasma cells, which, at times, invaded the hepatic sinusoids. Regenerative alterations were observed after 10 days p.i. and continued to be present after day 30 . The changes observed in the liver parenchyma were markedly attenuated 15 days p.i., but persisted after day 30 at a lower intensity.
Immunohistochemical staining of viral antigen (Fig. 4A) in the livers of hamsters infected with ROCV was intense between day 1-15 p.i. and decreased between day 16-30, with low but persistent levels being observed thereafter.

The lungs of hamsters infected with ROCV were characterised by thickening of the alveolar walls due to oedema, congestion and mononuclear infiltration (Fig. $3 \mathrm{H}, \mathrm{I})$. In addition, areas of overt pneumonitis and necrotic foci were observed. However, there were no overt signs of parenchymal condensation that would histopathologically characterise pneumonia or areas or foci of haemorrhage. The histopathological changes in the lung peaked on day 7 p.i., then remained stable until day 15
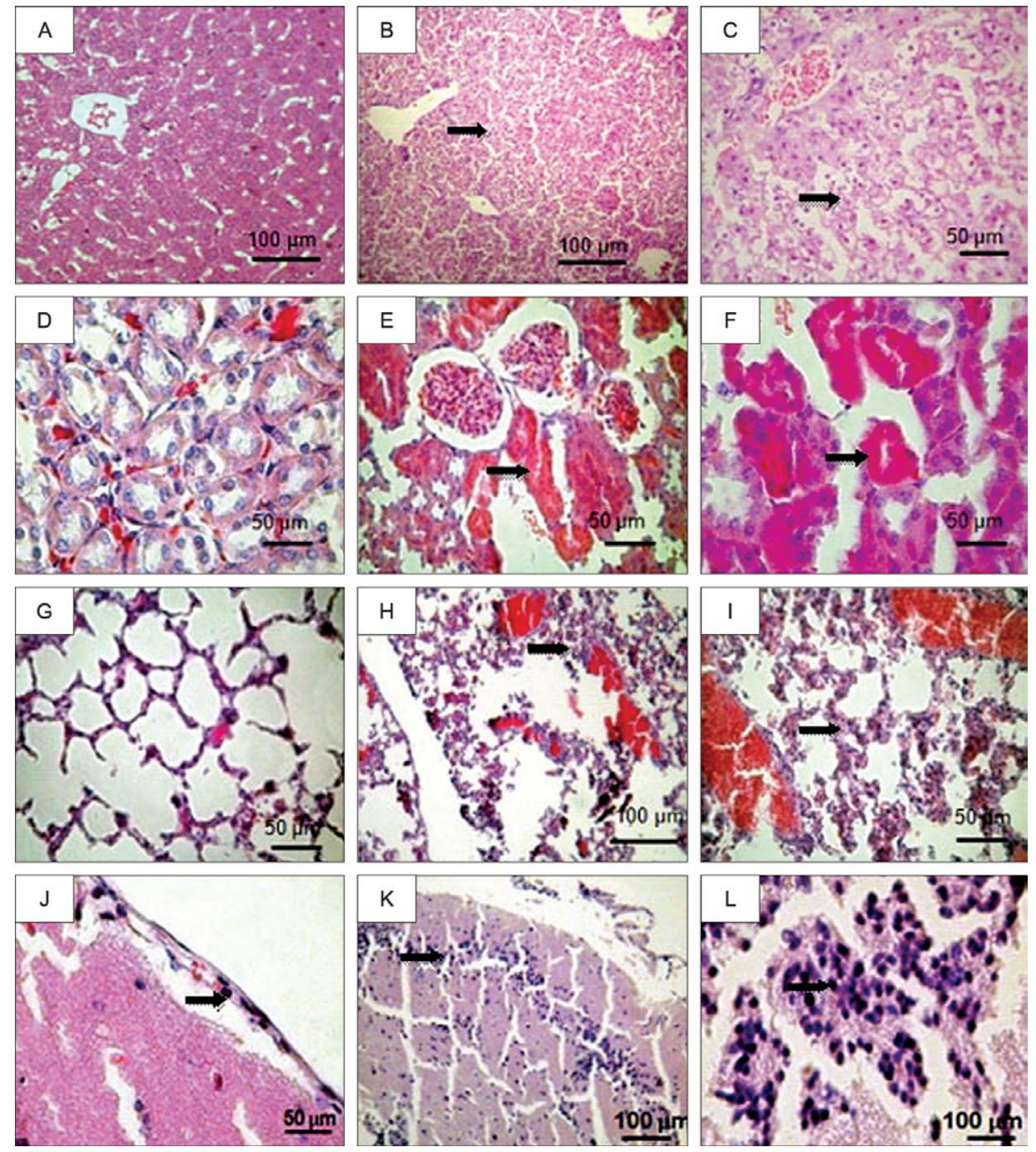

Fig. 3: photomicrographs of haematoxylin-eosin-stained specimens obtained from hamsters infected with Rocio virus. A: liver of an uninfected control animal; B: liver showing hepatocyte ballooning and portal spaces with a mononuclear infiltrate (arrow), 75 days post-infection (p.i.); C: liver showing some hepatocytes with reactive/regenerative or pyknotic nuclei (arrow), 75 days p.i.; D: kidney of an uninfected control animal; E: renal tissue showing congested glomeruli (arrow), 75 days p.i.; F: renal tissue showing swollen tubular epithelium and a mononuclear inflammatory infiltrate in the interstitium (arrow), 75 days p.i.; G: lung of a control animal; H: lung tissue showing thickening of the alveolar walls due to congestion, oedema and mononuclear infiltration (arrow), three days p.i.; I: lung tissue showing the alterations (arrow) seen in panel $\mathrm{H}$, three days p.i.; J: meninges of the central nervous system (CNS) showing a mononuclear inflammatory infiltrate and congestion (arrow), three days p.i.; K: CNS showing alterations characterized by reactive gliosis and oedema (arrow), 75 days p.i.; L: CNS showing reactive gliosis (arrow), 75 days p.i. 
and improved substantially between days 15-30. Minimal alterations were observed 30 days p.i.

Viral antigen was detected in the pulmonary parenchyma of animals infected with ROCV. The immunostaining was similar to that observed in the liver, with the highest intensity observed until day 15 p.i. The staining intensity declined thereafter and persisted at a low level after day 30 .

Congested glomeruli associated with oedema and foci of necrosis were observed in the kidneys of infected hamsters (Fig. 3E). A mild infiltrate, consisting of lymphocytes and plasma cells, was primarily observed in the interstitium of the renal parenchyma (Fig. 3F). Cellular swelling was observed at the tubular level, as were discrete foci of tubular necrosis. These alterations peaked on day 7 p.i., continued until day 15 and improved after day 17 p.i. The inflammatory process and tubular cell swelling continued after day 30 p.i.

Immunostaining for viral antigens in the kidneys (Fig. 4B) of hamsters infected with ROCV was positive in the renal parenchyma, with peak intensity on day 7 p.i. The immunostaining intensity remained high until day 15 p.i., then decreased thereafter and persisted at discrete levels after day 30 .

Congestion and mononuclear infiltration of the meninges were observed in the CNS of animals infected with ROCV (Fig. 3J). This infiltration was associated with intraparenchymatous oedema characterised by the presence of vacuolisation around neuronal bodies and cerebral gliosis (Fig. 3K). No alterations were apparent in the Virchow-Robin spaces and no cerebral gliosis or glial nodules were observed. These alterations peaked between day 7-8 p.i. and remained at a similar level until day 15 , followed by attenuation between day 16-30 and low-level persistence thereafter.

The analysis of the brains of hamsters infected with ROCV showed positive immunostaining for viral antigen (Fig. 4C) in the cerebral parenchyma. The staining intensity was more prominent between day 1-7 p.i. and persisted at low levels after day 15 .

\section{DISCUSSION}

The results of this study demonstrate that young hamsters are an appropriate experimental model for the study of ROCV infection. In addition to acute infection, these animals were also susceptible to persistent infection.

Infected hamsters developed viraemia, which was detected by an IFA of the supernatants of cell cultures inoculated with blood, for a maximum period of four days p.i. Antibodies detectable by HI appeared in the serum of infected animals on day 5 p.i., which coincided with the disappearance of the virus from the blood. This phenomenon was also observed by Tesh et al. (2005) in a study of the persistent infection of hamsters with West Nile virus. No viraemia was detected in the animals in this previous study after the appearance of $\mathrm{HI}$ antibodies, most likely due to the presence of neutralising antibodies that bind to the virus to form immune complexes that prevent the entry of the virus into uninfected cells and, consequently, viral replication. These complexes are then eliminated from the organism via immune defence mechanisms.
Viable viral particles were detected in the supernatants of all of the cells infected with material from organs, blood, serum and urine, thus confirming infection. Viral replication was demonstrated by a positive IFA, but persistence of the virus in Vero cells was not observed. However, direct culture of infected organs is most likely not the best strategy for the evaluation of persistent viral infection, as suggested by Xiao et al. (2001) and Siirin et al. (2007) in studies of West Nile virus and Saint Louis encephalitis virus, respectively. Intracellular virus particles released during the maceration of the organ fragments may come into contact with antibodies present in the blood and interstitial fluids, thus reducing the sensitivity of this method for the demonstration of viral persistence. The authors suggested that co-culture is more appropriate for the demonstration of persistent infection with flaviviruses because washing the tissue with trypsin-EDTA during preparation of the specimen presumably eliminates almost all neutralising antibodies without destroying the intracellular virus, which is subsequently released and amplified by co-culture with the Vero cell monolayer (Tesh et al. 2005).

Urine has been shown to be a good clinical specimen for the isolation of flaviviruses and to demonstrate viral persistence in direct cultures of Vero cells (Tesh et al. 2005, Tonry et al. 2005, Siirin et al. 2007). In the present experiment, the virus was isolated from urine, demon-
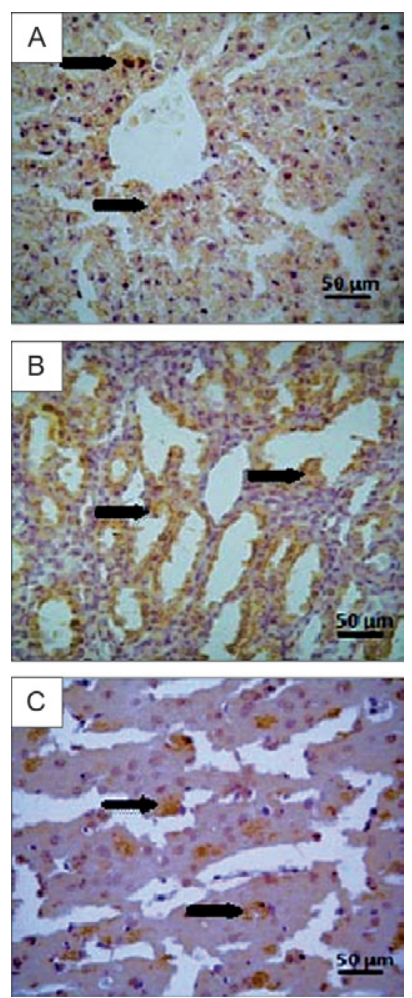

Fig. 4: representative photomicrographs of the immunohistochemical analysis of organs of golden hamsters infected with Rocio virus. A positive result appears as brown staining (arrow) in tissues. A: liver tissue, six days post-infection (p.i.); B: renal tissue, five days p.i.; C: central nervous system tissue, five days p.i. 
strating that the urine of infected animals is infectious. However, in studies reporting good viral isolation from urine, the urine was diluted in PBS before inoculation into Vero cells. In the present study, the urine was directly inoculated into Vero cells at a final dilution of 1:50 and the toxicity of the urine to the Vero cells may have influenced the results obtained. $q$ RT-PCR permitted the detection of even small concentrations of the virus in urine. The final three urine samples collected during the ROCV kinetic analysis (30, 60 and 75 days p.i.) were selected for analysis by $q$ RT-PCR and the results were positive at 30 and 60 days, with titres of 1.1 and 0.67 $\mathrm{PFU} / \mathrm{mL}$, respectively (data not shown).

ROCV was detected in all samples tested by $q$ RTPCR (blood, liver and brain), indicating the persistence of the viral infection. Viral RNA was detected until the end of the experiment ( 3 months). The sensitivity of $q$ RT-PCR for viral detection is as high as $99.09 \%$ (Yong et al. 2007, Nunes et al. 2011). $q$ RT-PCR is even able to detect the genome of inactive viruses. In fact, $q$ RT-PCR was much more sensitive than IFA, which only detected viral antigens in the supernatants of cells infected with brain samples collected prior to six days p.i. (Table).

ROCV caused pathological alterations in the hamsters and viral antigens were expressed in the liver, kidney, lung and brain samples during the four months of the experiment. The pantropic ROCV infection caused inflammatory lesions in the CNS, liver, kidney, spleen, lung and heart. The intensity and extent of tissue damage varied among the different organs. The damage was more intense damage in the CNS, which was expected because ROCV has previously been demonstrated to be neurotropic (Lopes et al. 1978, Iversson 1988), followed by the liver. These results were confirmed by immunohistochemistry and $q$ RT-PCR. The effect on the CNS is in agreement with the severity of the ROCV-induced human encephalitis during an epidemic that occurred in SP (Tiriba 1975, Iversson 1988).

The severe CNS injuries, including neuronal damage to the cerebral parenchyma or meninges, which caused meningitis associated with an inflammatory infiltrate that persisted for four months, further demonstrates the neurotropism and capacity of ROCV to cause encephalitis in hamsters. According to some authors, neuronal infection may facilitate the persistence of the virus in the brain. Mature neurons are more resistant to the induction of apoptosis. This resistance is possibly mediated by the neuronal expression of apoptosis inhibitors such as bcl-2, bcl-x and mcl-1, which are activated as a mechanism of neuronal preservation. These cells are also deficient in cellular components necessary for the presentation of antigens to cytotoxic $\mathrm{T}$ cells, i.e., they are deficient in the expression of major histocompatibility complex class I molecules (Griffin 1995).

No viral antigens could be detected by immunohistochemistry in spleen or heart fragments infected with ROCV, even though the virus replicated in Vero cells inoculated with these fragments, and there was evidence of alterations in these tissues. This suggests that the virus that grew in the Vero cells was present in the blood passing through these organs. The presence of the virus in the blood may have been responsible for the tissue damage and co-culture with Vero cells or $q$ RT-PCR is necessary to demonstrate the persistence of viral infection observed in the brain and liver.

Although the criteria used for the definition of persistence are arbitrary (Chambers \& Diamond 2003), according to the classification of persistent infection proposed by Santos (2008), the present results suggest that ROCV causes a chronic persistent infection in which the virus is continuously replicated and excreted.

Taken together, the results obtained for ROCV here and those reported in other studies for different flaviviruses (Tesh et al. 2005, Tonry et al. 2005, Siirin et al. 2007) suggest that a variety of flaviviruses cause persistent infections in vertebrates and that the persistence of these viruses is not a rare phenomenon. However, further studies are needed to determine exactly how a persistent ROCV infection is established, including the route by which the virus enters the CNS, the cells that permit infection of the CNS and the cell groups involved in the production of virus and in the protective immune response, as well as other aspects of pathogenesis.

\section{REFERENCES}

Beaty BJ, Calisher CH, Shope RE 1989. Arboviruses. In NJ Schmidt, EW Emmons, Diagnostic procedures for viral, rickettsial and chlamydial infections, 1st ed.. American Public Health Association Press, Washington, p. 797-855.

Carvalho VL, Nunes MRT, Silva EVP, Vieira CMA, Gomes M, Casseb SM, Rodrigues SG, Nunes-Neto JP, Quaresma JAO, Vasconcelos PFC 2009. Genetic characterization of orthobunyavirus Melao, strains BE AR633512 and BE AR8033, and experimental infection in golden hamsters (Mesocricetus auratus). $J$ Gen Virol 90: 223-233.

Chambers TJ, Diamond MS 2003. Pathogenesis of Flavivirus Encephalitis. In TJ Chambers, TP Monath, The Flaviviruses: pathogenesis and immunity, Vol. 60, Elsevier Academic Press, San Diego, p. 273-316.

Clark DH, Casals J 1958. Technique for haemagglutination and haemagglutination inhibition with arthropod-borne viruses. $\mathrm{Am} J$ Trop Med Hyg 7: 561-573.

Fauquet CM, Mayo MA, Manillof J, Desselberger U, Ball LA 2005. Family Flaviviridae. CM In Fauquet, MA Mayo, J Manillof, U Desselberger, LA Ball, Virus taxonomy, Elsevier Academic Press, London, p. 981-988.

Griffin DE 1995. Arboviruses and the central nervous system. Springer Sem Immunopath 17: 121-132.

Iversson LB 1988. Rocio encephalitis. In TP Monath, The arboviruses: epidemiology and ecology, CRC Press, Florida, p. 77-93.

Iversson LB, Coimbra TLM, Travassos da Rosa APA, Monath TP 1992. Use of immunoglobulin M antibody capture enzyme-linked immunosorbent assay in the surveillance of Rocio encephalitis. J Braz Assoc Adv Sci 44: 164-166.

Karabatsos N 1985. International catalogue of arboviruses, including certain other viruses of vertebrates, 3rd ed., American Society of Tropical Medicine and Hygiene, San Antonio, 1141 pp.

Kuno G 1998. A manual of cell culture techniques for small arbovirus diagnostic laboratories, Center for Disease Control, NCID/DVBID/ADB 970-221-6400, Fort Collins, 87 pp.

Lennette DA 1995. General principles of laboratory diagnostic methods for viral, rickettsial and chlamydial infections. In EH Lennette, DA Lennette, ET Lennette, Diagnostic procedures for vi- 
ral, rickettsial and chlamydial infections, 7 ed., American Public Health Association Press, Washington, p. 3-25.

Lopes OS, Coimbra TLM, Saccheta LA, Calisher CH 1978. Emergence of a new arbovirus disease in Brazil. I. Isolation and characterization of the etiologic agent, Rocio virus. Am J Epidemiol 107: 444.

Mitchell CJ, Forattini OP, Miller BR 1986. Vector competence experiments with Rocio virus and three mosquito species from the epidemic zone in Brazil. Rev Saude Publica 20: 171-177.

Nunes MRT, Palacios G, Nunes KNB, Casseb SMM, Savji N, Lipkin WI, Vasconcelos PFC 2011. Evaluation of two molecular methods for the detection of yellow fever virus genome. $J$ Virol Meth 174: $29-34$

Oldstone MBA 2005. Viral persistence: parameters, mechanisms and future predictions. Virology 341: 111-118.

Pinheiro FP, Travassos da Rosa APA, Vasconcelos PFC 1997. Arboviroses. In R Veronesi, R Focaccia, Tratado de infectologia, Atheneu, São Paulo, p. 169-180.

Prophet EB, Millis B, Arrington IB, Sobin LM 1992. Laboratory methods in histotechnology, American Registry of Pathology, Washington, p. 3-80.

Santos NOS 2008. Patogenese das Infecções Virais. In NSO Santos, VTM Romanos, DM Wigg, Introdução à virologia humana, 2nd ed., Guanabara Koogan Press, Rio de Janeiro, p. 42-58.

Shope RE 1963. The use of a microhaemagglutination-inhibition test to follow antibody response after arthropod-borne virus infection in a community of forest animals. Ann Microbiol 11: 167-171.

Siirin M, Duan T, Lei H, Guzman H, Travassos da Rosa APA, Watts MD, Xiao SY, Tesh RB 2007. Chronic St. Louis encephalitis virus infection in the golden hamster (Mesocricetus auratus). Am J Trop Med Hyg 76: 299-306.

Straatmann A, Torres SS, Vasconcelos PFC, Travassos da Rosa APA, Rodrigues SG, Tavares-Neto J 1997. Evidências sorológicas da circulação do arbovírus Rocio (Flaviviridae) na Bahia. Rev Soc Bras Med Trop 30: 512-525.
Tesh RB 1979. A method for the isolation and identification of dengue viruses using mosquito cell cultures. Am J Trop Med Hyg 28: 1053-1059.

Tesh RB, Siirin M, Guzman H, Travassos da Rosa APA, Xiaoyan W, Duan T, Lei H, Nunes MR, Xiao SY 2005. Persistent West Nile infection in the golden hamster: studies on its mechanism and possible implications for other flavivirus infection. $J$ Infect Dis 192: $287-295$.

Tiriba AC 1975. Epidemiologia de encefalite atribuida a arbovirus, ocorrida no litoral sul do estado de São Paulo em 1975: contribuição para o estudo clínico, $\mathrm{PhD}$ Thesis, Escola Paulista de Medicina, São Paulo, 202 pp.

Tiriba AC, Miziara AM, Lourenço R, Costa CRB, Costa CS, Pinto GH 1976. Encefalite humana primária epidêmica por arbovírus observada no litoral sul do estado de São Paulo. Rev Assoc Med Bras 22: 415

Travassos da Rosa APA, Pinheiro FP, Travassos da Rosa JFS, Vasconcelos PFC 1997. Arboviroses. In RNQ Leão, Doenças infecciosas e parasitárias, CEJUP-UEPA/Instituto Evandro Chagas, Belém, p. 207-226.

Tonry JH, Xiao SY, Siirin M, Chen H, Travassos da Rosa APA, Tesh RB 2005. Persistent shedding of West Nile virus in urine of experimentally infected hamsters. Am J Trop Med Hyg 72: 320-324.

Vasconcelos PFC, Travassos da Rosa APA, Pinheiro FP, Shope RE, Travassos da Rosa JFS, Rodrigues SG, Dégallier N, Travassos da Rosa ES 1998. Arboviruses pathogenic for man in Brazil. In APA Travassos da Rosa, PFC Vasconcelos, JFS Travassos da Rosa, An overview of arbovirology in Brazil and neighboring countries, Instituto Evandro Chagas, Belém, p. 72-94.

Yong YK, Thayan R, Chong HT, Tan CT, Sekaran SD 2007. Rapid detection and serotyping of dengue virus by multiplex RT-PCR and real-time SYBR green RT-PCR. Singapore Med J 48: 662.

Xiao SY, Zhang H, Guzman H, Tesh RB 2001. Experimental yellow fever virus infection in the golden hamster (Mesocricetus auratus). J Infect Dis 183: 1437-1444. 